\title{
A clinical study on role of caroverine in the management of tinnitus
}

\author{
Abha Kumari $^{1 *}$, Sandeep Kumar ${ }^{2}$
}

${ }^{1}$ Department Pharmacology, ${ }^{2}$ Department of ENT, Rajendra Institute of Medical Sciences, Ranchi 834009, Jharkhand, India

Received: 05 November 2016 Accepted: 09 December 2016

\section{*Correspondence to:}

Dr. Abha Kumari,

Email:

abhakumaridoc@yahoo.com

Copyright: (C) the author(s), publisher and licensee Medip Academy. This is an openaccess article distributed under the terms of the Creative Commons Attribution NonCommercial License, which permits unrestricted noncommercial use, distribution, and reproduction in any medium, provided the original work is properly cited

\begin{abstract}
Background: Tinnitus is a perception of sound in the absence of sound stimulation and it continues to be a significant and costly health problem without a uniformly accepted treatment. The signals between the inner hair cells and the cochlear nerve fibres are most likely to be transmitted by glutamate. Hence, present study was undertaken to assess the role of caroverine which is a glutamate receptor antagonist in the management of sensory neural tinnitus.

Methods: The present study was conducted among 50 adult patient with sensory neural tinnitus divided into two groups with 25 patients in each group. In group 1 caroverine $20 \mathrm{mg}$ twice daily for a period of 90 days was administered and in group 2 placebos was given. The effect of caroverine and placebo on subjective relief and objective improvement was evaluated by using THI (Tinnitus Handicap, Inventory) scoring, Tinnitus frequency matching before and after the administration of caroverine and placebo.

Results: In Group I reduction in tinnitus was seen in 16 patients (64\%) in 90 days. In group II (placebo group) improvement was seen in $20 \%$ of the patient. Significant difference with respect to treatment was noted. In group 1,8\% of the patient showed complete relief from the tinnitus. $44 \%$ of the patient showed improvement below $50 \%$ whereas $12 \%$ of the patient showed improvement more than $50 \%$.
\end{abstract}

Conclusions: Carvoverine had shown a statistically significant improvement in tinnitus management.

Keywords: Caroverine, Placebo, Tinnitus

\section{INTRODUCTION}

Tinnitus is defined as a perception of a sound without an external acoustic source. Tinnitus continues to be a significant and costly health problem without a uniformity accepted treatment. Estimates of patients with tinnitus range from $10-15 \%$ of the population. ${ }^{1}$ There are two categories of tinnitus. Subjective tinnitus is the perception of sound in the absence of an acoustic stimulus and is heard only by the sufferers, whereas objective tinnitus is the generation of sound near the ear that can be heard by the examiner. ${ }^{2}$

Jastreboff PJ proposed the discordant dysfunction theory for tinnitus, according to which outer hair cells (OHC) are damaged earlier to inner hair cells (IHC). ${ }^{3} \mathrm{OHC}$ provides amplification of sound within the cochlea whereas IHC is mainly concern with sound transduction. Cochlear damage leads to spontaneous firing of neuron in dorsal cochlear nucleus (DCN). ${ }^{4}$ A biochemical theory was proposed based on the connection between the inner hair cells and auditory nerve mediated by neurotransmitters. The most common excitatory neurotransmitters are glutamate while the primary inhibitory neurotransmitter is GABA. Both classes of inotropic glutamate receptor subtype, N-methyl-Daspartate (NMDA) and $\alpha$-amino-3-OH-Smethylsoxazole-4-proponic acid (AMPA) are present in afferent nerve fibres of inner hair cells. ${ }^{5}$ Increase in the release of glutamate has been suggested to be involved in the generation and maintenance of sensory neural tinnitus by causing excitotoxicity and thus over expression of NMDA receptors. 
Caroverine is a quinoxaline derivative and belongs to papaverine group. Caroverine is glutamate receptor antagonist and also has other activities, which reduces the excitability of the nerve cell function. These activities include calcium antagonism. ${ }^{6}$ It is postulated that caroverine blocks both NMDA and AMPA induced firing. Hence, present study was undertaken to assess the role of caroverine which is a glutamate receptor antagonist in the management of sensoryneural tinnitus.

\section{METHODS}

The present prospective, randomized and placebo controlled study was conducted to evaluate the efficacy of caroverine in the management of tinnitus. Ethical committee of the institute granted the ethical permission for carrying out the study. The written consent was obtained from the entire patient after explaining them the research steps involved. In this study 50 adult patient (>30 years of age) suffering from unilateral or bilateral tinnitus with or without hearing loss present in outpatient department were included. Pregnant, lactating patient, history of chronic suppurative otitis media, objective tinnitus, and history of exposure to ototoxic drugs were excluded from the study. They enrolled patients were divided into two groups of 25 patients in each. Group I were treated with caroverine $20 \mathrm{mg}$ capsule twice daily for 90 days. Group II were treated with placebo for 90 days. A complete medical and ENT examination with detailed history were taken from all the patients. All the patients were subjected to Tunning Fork test, Pure Tone Audiometry (PTA), Impedance Audiometry, Tinnitus matching in term of frequency and intensity, MRI of Brain and temporal bone. The Tinnitus Handicap Inventory Questionnaire (THI) scoring of the patients was done before and after the study. The results were compiled and analysed statistically by using students ' $\mathrm{t}$ ' test with $\mathrm{p}$ value $<0.05$ as significant value. ${ }^{7}$

\section{RESULTS}

In the present study $40 \%$ of the patients (20 patients) were of normal hearing where as $60 \%$ of the patient (30 patients) were suffering from Sensory Neural hearing loss. Male and Female ratio in each group are shown in Table 1. Most of the patient had tinnitus intensity between 41-50 dB. Mean and standard deviation of THI values is given in Table 2. No significant difference was noted with respect to gender.

Table 1: Distribution of patients according to age and gender.

\begin{tabular}{|lllll|}
\hline Group & \multicolumn{2}{l|}{ Group 1 } & \multicolumn{2}{l|}{ Group 2 } \\
\hline Age (in years) & Male & Female & Male & Female \\
\hline $31-40$ & 4 & 3 & 5 & 3 \\
\hline $41-50$ & 5 & 6 & 6 & 5 \\
\hline $51-60$ & 4 & 3 & 3 & 3 \\
\hline Total & 13 & 12 & 14 & 11 \\
\hline
\end{tabular}

Table 2: Mean and standard deviation of Tinnitus Handicap Inventory (THI) values.

\begin{tabular}{|c|c|c|}
\hline $\begin{array}{l}\text { Tinnitus Handicap } \\
\text { Inventory (THI) } \\
\text { values }\end{array}$ & $\begin{array}{l}\text { Mean } \pm \\
\text { Standard } \\
\text { deviation }\end{array}$ & P value \\
\hline Male & $32 \pm 12$ & \multirow{2}{*}{$\begin{array}{l}>0.05 \text { (not } \\
\text { significant) }\end{array}$} \\
\hline Female & $34 \pm 16$ & \\
\hline
\end{tabular}

In Group I reduction in tinnitus was seen in 16 patients $(64 \%)$ in 90 days. In group II (placebo group) improvement was seen in $20 \%$ of the patient (Table 3 ). Significant difference with respect to treatment was noted. In group $1,8 \%$ of the patient showed complete relief from the tinnitus. $44 \%$ of the patient showed improvement below $50 \%$ whereas $12 \%$ of the patient showed improvement more than 50\% (Table 4, Figure 1).

Table 3: Improvement in tinnitus in both groups.

\begin{tabular}{|lll|}
\hline Groups & $\begin{array}{l}\text { N }(\%) \text { of patients that } \\
\text { showed: Improvement } \\
\text { in tinnitus }\end{array}$ & p-value \\
\hline Group 1 & $16(64 \%)$ & $\begin{array}{l}<0.05 \\
\text { (significant) }\end{array}$ \\
\hline $\begin{array}{l}\text { Group 2 } \\
\text { (placebo) }\end{array}$ & $5(20 \%)$ & . \\
\hline
\end{tabular}

Table 4: Improvement in tinnitus after caroverine treatment (group 1).

\begin{tabular}{|l|l|}
\hline $\begin{array}{l}\text { \% of improvement in Tinnitus } \\
\text { after Caroverine Treatment }\end{array}$ & $\%$ of patients \\
\hline$<50 \%$ & $44 \%$ \\
\hline$>50 \%$ & $36 \%$ \\
\hline No Improvement & $12 \%$ \\
\hline $100 \%$ & $8 \%$ \\
\hline
\end{tabular}

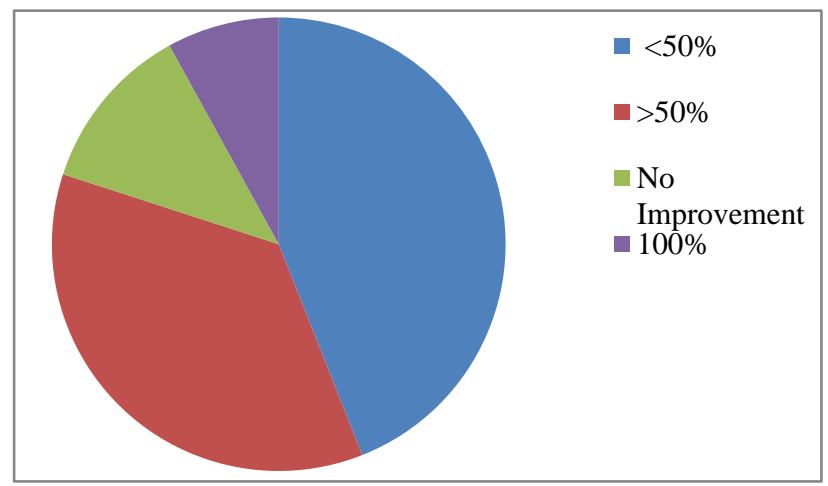

Figure 1: Improvement in tinnitus after caroverine treatment.

\section{DISCUSSION}

Tinnitus has been reported in about $15 \%$ of the world population, most of them between the ages of 40 and 80 years. ${ }^{8}$ In the present study, maximum number of patients were in age group of 41-50 years. Al-Swiahb $\mathrm{J}$ et al 
reported that the mean age of tinnitus patients among women was 54 years and among men was 51.5 years. ${ }^{8}$ Martines $\mathrm{F}$ et al found an heterogeneous distribution of age among tinnitus patients with $65.7 \%$ of people with more than fifty years of age. ${ }^{9}$

The pathophysiology of tinnitus is one of the most controversial issues in medical science. Tinnitus is associated with several risk factors, such as prolonged noise exposure, head/neck injury and infections. The newer pathophysiology theory suggests that the central nervous system is the source or generator of tinnitus. Functional magnetic resonance imaging and positron emission tomography scan of the inner ear and brain show a loss of cochlear input by cochlear hair cell damage or a lesion of the auditory nerve to the central auditory system can lead to abnormal neural activity in the auditory cortex area. ${ }^{10}$ The main etiologic factors associated to tinnitus include acoustic trauma (especially chronic noise exposure), presbycusis, otosclerosis and various drugs linked to tinnitus such as antinflammatories (aspirin and quinine), antibiotics (aminoglycosides), loop diuretics, chemotherapeutic agents (such as cisplatin and vincristine) and antidepressants (amitriptyline, imipramine). Other risk factors are smoking, hypertension, diabetes mellitus and dyslipidemia. ${ }^{11}$

Most forms of Tinnitus are described as cochlear synaptic tinnitus. This is a condition where the inner hair cells have been damaged by noise exposure, ototoxic drugs or Meniere's disease. Glutamate is known to be the important neurotransmitter in the CNS and the signals between inner hair cells and the cochlear afferent neuron fibres. The functional damage of inner hair cells leads to excess production of glutamate and the glutamate receptors in the cochlea become excited with higher dose of glutamate. The excessive glutamate binds to NMDA receptors which lead to calcium and sodium to enter the neuron leading to spontaneous depolarisation. ${ }^{6,12}$

Tinnitus treatments can be divided into two categories, those aimed at directly reducing the intensity of tinnitus and those aimed at relieving the annoyance associated with tinnitus. The former include pharmacotherapy and electrical suppression, and the latter include pharmacotherapy, cognitive and behavioural therapy, sound therapy, habituation therapy, massage and stretching, and hearing aids. Although numerous therapeutic modalities have been applied, no consensus regarding effective therapeutic agents has emerged. ${ }^{2}$

Hence, the present study was undertaken to assess the role of caroverine which is a glutamate receptor antagonist in the management of sensoryneural tinnitus.

Caroverine is an oto- neuroprotective agent having the antioxidant property also. It acts as an N-Type calcium channel blocker, competitive AMPA receptor antagonist and non-competitive NMDA receptor antagonist. [AMPA is 2-amino-3-(5-mehtyl-3-oxo-1,2-oxazol-4-yl) propionic acid.whereas NMDA is N-methyl D- Aspartate]. ${ }^{13,14}$ Spontaneous depolarisation of NMDA receptor can be reversed to physiological polarization by antagonist property of caroverine. In the present study improvement in sensory neural tinnitus was observed in 16 patients $(64 \%)$.At the end of 90 days only 9 patients $(36 \%)$ showed no improvement or worsening of tinnitus. Eleven patients $(44 \%)$ showed improvement below $50 \%$ whereas 3 patients (12\%) showed improvement more than $50 \%$ in 2 patients $(8 \%)$ there was complete disappearance of tinnitus. In placebo group, improvement was seen in $20 \%$ of the patient. The helpful 'placebo' factors are seeing a professional, receiving a plausible treatment plan, and believing that the treatment will work. This placebo effect is often thought of as evidence of patient susceptibility to non-treatment factors, but in fact a closer look indicates that some patients do improve their health under such conditions. If the patient believes that are going to be helped by a treatment, even a sugar pill, then they often receive a real, beneficial effect'. In fact, this effect is sometimes accompanied by physiological changes. ${ }^{15}$

Ehrenberger $\mathrm{K}$ et al carried out a microiontophoretical experiment in guinea-pigs and found that caroverine acted as a potent competitive alpha-amino-3-hydroxy-5methyl-4-isoxazone-proprionic acid (AMPA) receptor antagonist and, in higher dosages, a non-competitive Nmethyl-d-aspartate (NMDA) antagonist. Denk DM et al performed a study to find out whether a single infusion of caroverine, a quinoxaline-derivative, can be used successfully in the treatment of inner ear tinnitus and found that $63.3 \%$ responded to therapy immediately after the infusion and in the placebo group, none of the patients treated showed a significant response. ${ }^{13,16}$ The present study was conducted among a limited number of patients. Thus, further studies with large sample size are required.

\section{CONCLUSION}

The results of present study conclude that carvoverine is effective in the management of tinnitus. However, sparse data is available regarding the same. Hence, further research should be directed towards the search of beneficial effect of caroverine in tinnitus. Caroverine could be a miracle medicine for cochlear synaptic tinnitus.

Funding: No funding sources

Conflict of interest: None declared

Ethical approval: The study was approved by the Institutional Ethics Committee

\section{REFERENCES}

1. Heller AJ. Classification and Epidemiology of Tinnitus. Otolaryngol clin North America. 2003;36:239-48.

2. Han BI, Lee HW, Kim TY, Lim JS, Shin KS. Tinnitus. Characteristics, Causes, Mechanisms, and 
Treatments. Journal of Clinical Neurology (Seoul, Korea). 2009;5(1):11-9.

3. Jastreboff PJ. Phantom auditory perception (tinnitus): mechanism of generation and perception. Neurosci Res. 1990;8:221-54.

4. Kaltenbach JA, God frey DA Dorsal Cochlear nucleus hyperactivity and tinnitus: Are they related? Am. J. Audiol. 2008;17:S148-61.

5. Guitton MJ, Wany J, Puel JL. New Pharmacological strategies to restore hearing and treat tinnitus. Acta Otolaryngol. 2004;124:411-15.

6. Domeisen H, Hotz MA, Hausler R. Caroverine in tinnitus treatment. Acta otolaryngol. 1998;118:606-8.

7. Newman CW, Jacobson GP, Spitzer JB. Development of tinnitus handicap Inventory. Arch Otolaryngol Head Neck surgery. 1996;122:143-48.

8. Al-Swiahb J, Park SN. Characterization of tinnitus in different age groups: A retrospective review. Noise Health. 2016;18:214-9.

9. Martines F, Bentivegna D, Martines E, Sciacca V, Martinciglio G. Assessing audiological, pathophysiological and psychological variables in tinnitus patients with or without hearing loss. Eur Arch Otorhinolaryngol. 2010;267:1685-93.

10. Swain SK, Nayak S, Ravan JR, Sahu MC. Tinnitus and its current treatment-Still an enigma in medicine. Journal of the Formosan Medical Association. 2016;115(3):139-44.
11. Salvago P, Ballacchino A, Agrifoglio M, Ferrara S, Mucia M, Sireci F. Tinnitus patients: etiologic, audiologic and psychological profile. Acta Medica Mediterranea. 2012;28:171-5.

12. Ceranic B, Luxon LM. Tinnitus and other dysacusis: Scott Brown's otorhinolaryngology and Head Neck surgery. $7^{\text {th }}$ ed. Great Britain: Hooder Arnold Ltd: 2008;3:3594-619.

13. Denk DM, Heinzl H, Franz P, Ehvenberger K. Caroverine in tinnitus treatment. A placebo controlled blind study. Acta otolaryngologica. 1997;117:825-30.

14. Ehnenberger K. Topical administration of caroverine in somatic tinnitus treatment: proof-of-concept study. Int. Tinnitus J. 2005;11:34-7.

15. Tyler RS. The use of science to find successful tinnitus treatments. Sixth International Tinnitus Seminar; 1999:4-10.

16. Ehrenberger K, Felix D. Caroverine depresses the activity of cochlear glutamate receptors in guinea pigs: in vivo model for drug-induced neuroprotection? Neuropharmacology. 1992;31(12):1259-63.

Cite this article as: Kumari A, Kumar S. A Clinical Study on Role of Caroverine in the Management of Tinnitus. Int J Basic Clin Pharmacol 2017;6:176-9. 